European Journal of Probation University of Bucharest www.ejprob.ro

Vol. 3, No.3, 2011, pp $78-94$ ISSN: $2006-2203$

\title{
'They were very threatening about do-gooding bastards': Probation's changing relationships with the police and prison services in England and Wales
}

\author{
Rob C Mawby ${ }^{1}$ \\ Anne Worrall ${ }^{2}$
}

\begin{abstract}
In recent decades the probation service has been encouraged to work closely with a range of public and voluntary sector agencies. This article examines probation's changing relationships with the police and prison services drawing on sixty interviews with current and former probation workers. Analysing probation-prison and probation-police relationships pre- and post-1998 and drawing on Davidson's (1976) typology of inter-organisational relationships, the article argues that, despite both structural and cultural transformations, there remain cultural continuities in each organisation that create tensions, the significance (both positive and negative) of which should not be under-estimated.
\end{abstract}

Keywords: Probation - Probation officers - Occupational cultures - Organisational relationships - Multi-agency relationships

\section{Introduction}

Relationships between the probation service and other criminal justice agencies in England and Wales have changed considerably in recent decades. Partnership working has been encouraged through the Crime and Disorder Act 1998, the Multi-Agency Public Protection Arrangements (MAPPAs), established by the Criminal Justice and Court Services Act 2000, the development of the Prolific and Priority Offender (PPO) schemes and, most recently, the

\footnotetext{
${ }^{1}$ Author responsible for correspondence, reprints and proofs.

Correspondence concerning this article should be addressed to Rob Mawby, 154 Upper New Walk, University of Leicester. United Kingdom. Email: rim3@le.ac.uk

${ }^{1}$ Professor Anne Worrall, Keele University and the University of Western Australia. Email: a.j.worrall@crim.keele.ac.uk
} 
establishment of Integrated Offender Management units. In addition, the relationship between the probation and prison services was formalised in 2004 when the two agencies were brought together to form the National Offender Management Service (NOMS). These ever closer formal relationships between agencies have not always been comfortable, raising issues of information sharing, conflicting objectives, different ways of working, contrasting attitudes towards offenders and, not least, cultural tensions. Although the probation service has important relationships with a range of public and voluntary sector agencies and with the courts, in this article our purpose is to map and make sense of the relationships with the police and prison services from the 1960s to the present.

The article draws on interview data to consider these relationships and some of their implications from the perspective of probation workers over five decades. It explores the significance of these relationships for: the role of probation workers and their perceptions of it; the self-identities of probation workers and how they feel they are perceived by other agencies; and the effectiveness of criminal justice processes. While the charting of these relationships is interesting in itself for the rich data it reveals, to add critical purchase we overlay the data with a consideration of models of organisational interaction. We do this not to identify best practice models of partnership working, but rather to aid interpretation of the significance of the changing relationships.

The data that underpin this article are taken from semi-structured interviews conducted with sixty current and former probation workers across England and Wales between June 2010 and March 2011 as part of an ESRC-funded project to examine how probation workers view themselves and their role ${ }^{1}$. The participants ranged in experience from newly qualified to retired probation officers in their seventies. The sample included all grades in the probation service hierarchy ${ }^{2}$.

We begin with a discussion of the interactions between criminal justice agencies and how these have been conceptualised. From this we put forward Davidson's (1976) model as a framework for understanding these organisations and their relationships. We then discuss probation-prison and probation-police relations pre- and post- 1998, arguing that a potential 'tipping point' was reached in 1998 when a political consensus acknowledged that the probation service's community-facing role was set to develop more strongly than its custodyfacing role (a consensus that was to disintegrate within five years). We conclude that, while structural and cultural transformations in the three organisations presaged the emergence of a generic criminal justice worker, they ultimately failed to establish the polibation/ prisobation officer because of the tenacity of cultural continuities in each organisation.

\section{Working together}

Examination of the recent history of criminal justice in England and Wales provides examples of catalysts, encouraging agencies to work more closely together for the greater goods of crime prevention, community safety and, more latterly, risk management and public protection. These catalysts have included official reviews, policy initiatives, legislation and changes in recruitment and training regimes for criminal justice practitioners. Examples include: the Morgan Report (1991), which recommended 'a multi-agency approach to community safety' and is often cited as a starting point for partnership working; the Crime and Disorder Act 1998 putting partnership working on a statutory basis and creating 
'responsible authorities', and the creation of NOMS in 2004, providing, on paper at least, a seamless system for the efficient management of offenders.

These encouragements towards closer working relationships have practical and conceptual consequences, which are reflected in the scholarly and policy-oriented literature. On the one hand, at a conceptual level, writers have theorised the implications of greater collaborative working for role boundaries and the blurring of agency roles. In this regard Kemshall and Maguire (2001) wrote about the 'polification' of probation and Nash $(1999,2004,2008)$ has made incisive contributions on the entry and possible exit of the 'polibation' officer, the notion of which has been revisited (Mawby and Worrall 2004) and stretched to 'prisipolibation' (Mawby et al. 2007). At the heart of these works has been a debate concerning the loss of distinct roles and cultures that have provided valued checks and balances in the practice of criminal justice and a move towards the control of offenders, based on their assessed risk, for the benefit of public protection, which has become a central goal for the probation, prison and police services.

On the other hand, a more pragmatic literature has provided critiques of the character, strengths and weaknesses of partnership working, primarily for the benefit of policymakers and practitioners (see, for example, Audit Commission 1998; National Audit Office 2001; Rumgay 2003; Berry et al. 2011). The two literatures are linked by the common theme of examining working relationships and modelling the agency interaction, albeit for differing purposes. To aid our analysis, we refer to Davidson's (1976) typology of inter-organisational relationships. Davidson developed a framework to assist planners to assess the viability of coordinated approaches to the delivery of services. He proposed a five stage typology with each stage representing a more complex level of interaction between organisations, namely: (1) communication, (2) cooperation, (3) coordination, (4) federation and, finally, (5) merger. To ascertain the viability of an 'interorganisational undertaking' and the best strategy to deliver it, Davidson identified a three stage framework in which planners consider in sequence: environmental pressures, organisational characteristics, and inter-organisational planning processes.

Davidson's framework remains relevant and his idea of a continuum or matrix of interaction has been used by many writers. For example, Poxton (2003) (in Glasby and Littlechild 2004) identifies four types of partnership working (communication, co-ordination, collaboration and integration). Such typologies can provide a means of benchmarking the level of working relationship between criminal justice agencies (as demonstrated by Thomas 1994). They can also provide explanatory power. For example, examination of Davidson's three sets of factors can help explain the existence and nature of organisational inter-relationship and the extent to which organisations and workers are prepared to negotiate and change, or 'mutually adjust' (Lindblom and Woodhouse 1993).

For an organisation to be propelled into working more closely with other organisations, there must exist an environment of political, economic and/or social 'turbulence', such that 'individual organisations, however large, cannot expect to adapt successfully simply through their own direct actions' (Emery and Trist 1965:24). But a 'turbulent field' is insufficient of itself to achieve closer working unless organisations can see clear benefits in terms of additional resources and, crucially, respect for what Davidson calls 'domain'. 'Domain' is the implicit agreement on the nature and extent of respective organisational integrity, i.e., mutual acknowledgement and respect for such things as agency purposes, geographic areas 
covered, services offered and client characteristics. Where one organisation has expansionist ambitions and little respect for the domain of the other, there is likely to be resistance to closer working. But even when domain is respected, closer working will only happen when the 'limits of rationality' are acknowledged (Davidson 1976:133). The existence of unresolved individual and group role conflict and the absence of leadership will prevent participants from acting rationally to achieve clear goals. Throughout this article the concepts of 'turbulence', 'domain' and the 'limits of rationality' as here defined aid our interpretation of the relationships between probation, police and prison officer occupational cultures.

We turn now to our interviewees' perceptions of the state of relationships between probation, prison and police officers in the period from the 1960s to the 1990s.

\section{Probation and prisons: from Prison Welfare to Shared Working}

Culturally and historically, probation officers have felt uneasy about working in prisons, as though by doing so they were 'colluding with something harmful' (Nellis 2007: 44). They took over responsibility for prisoner 'after-care' (later 'through-care' and even later 'resettlement') from the voluntary organisation, The National Association of Discharged Prisoners Aid Societies (NADPAS), in 1966, and prison welfare officers (PWOs) were appointed to every penal institution. The Service was renamed The Probation and After-Care Service for about 15 years until the early 1980s. Throughout that period, there were fierce debates both within the probation service and between it and the prison service about whether or not there should be probation officers located inside prisons at all.

The debate was both ideological and cultural. Ideologically, the service stood accused of colluding with a politics of expediency by 'keeping the lid on' the cauldron of discontent that characterised many prisons in the 1970s and 1980s. As Stanton (1985:107) argued, 'everybody knows what is wrong with the relationship between the probation service and the prison department, everybody knows that there is an essential difference of philosophy'. The primary task of the PWO, it was asserted, was to reduce prisoner anxiety (Othen 1975:100), thus making the prisoner easier to control and inducing in him a state of 'false consciousness' about the reality (political reality, that is) of his plight.

Culturally, there were two issues. First, there was a fear that probation officers working in prisons would become institutionalised or culturally acclimatised to an environment that was anathema to everything they stood and had been trained for. Othen was in no doubt that 'the problem for probation officers is not whether we can work in such terrible places, but the unpalatable fact that when we do we are a part of the dependency-producing, self-respectdestroying regime' (1975:102). Second, by defining themselves (or being defined) as 'The Welfare', probation officers were allegedly depriving basic grade prison officers of those aspects of their job that gave them the most satisfaction and stopped their role from being exclusively that of 'turnkey' or 'jailer'. In an interview for Probation Journal, John Bartell, the then new Chair of the Prison Officers Association, expressed the fear that 'we could be reduced to merely doing the menial task of fetching and carrying prisoners' (Stone 1985:85). Others have argued that this view is disingenuous and that the POA's real aim was to clear the prison of 'civilians' (Leech 1991). 
What, then, were the tasks of PWOs in this era? Othen (1975:99) set the scene thus:

Letters astray, forgotten or crossed; breaking of bad news and coping with feelings aroused; obtaining news of sickness, birth, death; why relatives/ object of heart's desire has not visited; urgent visits, extra visits; coping and helping to reduce excessive anxiety; parole interviews; commiseration/ 'be patient my son' interviews in long term establishments; flood of receptions and discharges in others.

In sum, PWOs had three roles: working directly with prisoners, liaising with probation service colleagues in the community and co-operating with prison staff to ensure the smoothrunning of the prison. Of these, it was the first that brought them into conflict with prison staff and the last that attracted criticism from probation service colleagues, especially those who belonged to the National Association of Probation Officers, whose policy became to withdraw probation staff from prisons and increase resources for prisoner after-care in the community (Glanfield 1985). The second role, that of liaising with probation colleagues in the community, was uncontentious in principle but criticised in practice because 'outside' and 'inside' probation officers were mutually accusatory about each others' competence and commitment to prisoners (Williams 1991).

Our research confirms that prisons were pretty unpleasant places in which to work in this era. Leaving aside the overcrowding, slopping-out and crumbling buildings, an atmosphere of thinly-veiled violence was pervasive:

My abiding memory is two uniformed officers grabbing me by the lapels, hanging me up against the wall, and I don't actually remember their exact words now but they were very threatening about do-gooding bastards. (CO1)

We heard stories about sexism (for example, the female PWO who was summonsed to the censor's office to give 'advice' about letters containing graphic sexual messages, women not allowed keys or on the landings) and racism (for example, the black gate officer openly known as 'Black Bob' and the wearing of National Front badges on prison uniforms).

Others recognised that being a prison officer wasn't perhaps the easiest of jobs:

I'm not saying you had to cow-tow to them... but you had to respect their position because they were doing a difficult job, sometimes a pretty revolting job...you know, you had prisoners defecating in their cells... and riots...you know, some had witnessed hangings and I mean horrible things they had to deal with. (FPW8)

And that there were ways of getting what you wanted if you were prepared to swallow some of your professional pride:

It was about how you treated them... if you talked down to a prison officer, you weren't gonna - it's not rocket science. But some of my colleagues didn't understand that you needed to be careful with the way you handled other professions. (FPW5)

Such views acknowledge Kreiner et al's (2006) argument that being a prison guard ranks among the most pervasively stigmatised 'dirty' occupations. Kreiner et al. categorise prison guards as being socially tainted because they work with people despised by society but they place less emphasis on the physically tainted work highlighted in the above quotation. 
Probation officers, though sharing some of the social taint of prison guards, enjoy a somewhat higher social prestige (Ashforth and Kreiner 2007).

In 1972, Priestley analysed the situation of PWOs in terms of (a) society's ambivalence towards prisons, (b) the ill-defined role of the PWO, (c) role conflict and (d) institutional pressure. He offered four strategies for survival, redolent of the prisoner culture literature of the time: conformity, retreatism, innovation and rebellion. Pratt (1975) summarised the PWO's dilemma as that of visibility and strangeness. The role is both exposed and 'other' within the prison setting, resulting in both stress and opportunity. Contrary to Priestley's call for clearer role definition, Pratt argued for the role to remain undefined, at least for a while, so the PWOs could use their professional social work (note, social work) skills to develop innovative relationships that were appropriate to the setting. However, crucial to this development in a context of confrontational 'communication' and grudging 'co-operation' (Davidson 1976) was for the probation service to 'come to terms with its fear and distrust [of the prison service] and certainly abandon its arrogance' (Pratt 1975:395).

Despite NAPO's policy to withdraw probation officers from prisons, it was clear by the mid 1980s that they were going to stay and that there had to be some resolution to the ideological and cultural conflict between the probation and prison services. Increasingly both services were experiencing public sector managerialism and by 1988, the Home Office Minister of State, John Patten, was arguing that 'we're all in the business of punishment' and that 'it is bizarre to scratch around for polite euphemisms for what is going on' (Worrall and Hoy 2005: 33-34). In 1985, a report by Jepson and Elliott proposed 'shared working' between probation and prison officers and this, for the next 15-20 years, is more or less what happened.

'Shared working' was defined from the outset as not being social work but 'through-care' with an inter-disciplinary approach. There was no attempt to blur the boundaries between probation and prison officers but to get them working better together to achieve the same goals (Lacey and Read 1985), although it was conceded that this was an 'uphill struggle' (Fieldhouse and Williams 1986:143). It took many forms but the uniting themes were, first, 'through-care' (later 'resettlement') and, second, 'rehabilitation' in the specific form of 'what works' or 'evidence-based practice'. The term 'resettlement' was adopted by the Home Office in the late 1990s as an over-arching term that covered sentence planning inside the prison and reintegration into the community on release (Maguire 2007). Models of resettlement consisted of varying degrees of welfare assistance, problem-solving skills and, crucially, responsibilisation. The roles of prison and probation officers were viewed as being complementary and the development of cognitive behavioural programmes (such as Reasoning and Rehabilitation and the Sex Offender Treatment Programme) provided opportunities for both to work together in the same classroom (rather as probation and police officers were to work together in the community on prolific offender projects). Encouraging prisoners to accept responsibility for their actions, express victim empathy and improve their repertoire of responses to life problems was an agenda to which both prison and probation officers could subscribe and which necessitated their 'co-ordination' (Davidson 1976).

Although many probation officers still had no interest in working in prisons (and dreaded being required to do so), it was during this period that some of our interviewees recounted their most satisfying experiences of working in prisons: 
I got the job in the prison for six years, which was brilliant. It was a good move; it was worth waiting for. It was a wonderful time to be there. [My predecessor] had set up this really good system of working. Every [prisoner] on admission was seen at a board the next day with a senior [prison] officer or an officer and either me or one of my staff. ...And then, you would pick up on what the problems were and then between us, we would act on it. (FPW5)

We did quite a lot of joint work with prison officers. We did the offending behaviour group... there'd be one probation officer, one prison officer. Some were very good, some were very bad but that generally worked quite well. Yeah, we worked well together, yeah. (PW9)

So much did some probation officers enjoy working in prisons that chief officers had difficulty in persuading them to take jobs elsewhere. For some, working in prison was (and still is) an escape from the pressures of work in the community (PW2; PW9) but some just became institutionalised:

With staff I have seconded to prisons, I say, you come out after an absolute maximum of five years. And, of course, they don't want to. And I say, well you just become part of the institution... you get sucked in. It's a very invasive culture. (CO13)

But the cultural changes that facilitated shared working were not just in one direction. Prison officers may have felt freer to express an interest in offender rehabilitation, but probation officers were moving away from their image as 'the welfare' or 'care bears' and becoming increasingly comfortable with a 'disciplinary or enforcement approach' (PW9). And there was still a need for probation officers to tread warily in inter-personal relationships:

You have to play a game and the game is, you're a civilian, they will treat you as a second class citizen, you have no rights and there's no issue of professional courtesy...they will treat you as they see fit. So long as you know that....and you're basically nice, you pussyfoot around them and nicely-nicely, "oh could you do that, oh cheers, that great". And then you get what you want. (PW6)

They had a general collective view that we were just a complete waste of space and they didn't know why we were there. Then there was a different view based on how good you were, whether you actually did anything valuable, you know, on the wing, in terms of the way the wing ran. (PW5)

The election of New Labour to government in 1997 was to force this embryonic and still fragile partnership between the probation and prison services on at a much faster pace than either side was comfortable with. The desire of the government to erase the concept of probation from the collective conscience as a term too closely associated with the tolerance of crime (Worrall 2008: 117) led to the setting up of the Prisons-Probation Review to explore the possibility of integrating the two services. The consultation document reporting on the review and entitled Joining Forces to Protect the Public (Home Office 1998) rejected the merger of the two services, partly on grounds of principle (insufficient overlap of responsibilities) and partly on grounds of cost. In Davidson's terms, the report made the important distinction between merger and less integrated forms of interaction. It described the prospect of a full merger as being 'a bridge too far' and explicitly recognised that probation's role in the public protection agenda would involve it more in a range of inter-agency work in the community (not only police but mental health, local authorities, the Crown Prosecution Service, victim support and voluntary sector organisations) than in developing its relationship with prisons beyond that of the routine improvement of 'shared working'. Significantly, 
Joining Forces in 1998 acknowledged what the Carter Report (2003) later failed to grasp, namely, that the cultural tide for probation was already shifting towards a sense that it was the police and not the prisons who were its 'natural partners'.

But the relationship between probation and the police had, if anything, been more hostile historically.

\section{Probation and the police: mutual suspicion}

The aforementioned antipathy felt by probation officers towards working in prisons was matched by their disdain for the police, which also had ideological and cultural foundations. Ideologically, probation and police officers were regarded as occupying contrasting positions in the criminal justice system. On the one hand the police, as crime fighters, apprehended criminals with the objectives of preventing and detecting crime. On the other hand, probation officers' work focussed on the same group, but constructed them as 'clients' rather than criminals, and provided supervision with the objective of change and rehabilitation. With such different missions, it is not surprising that police and probation officers should come into conflict and develop distinctive occupational cultures based on contrasting world-views.

The relationship in tension is alluded to in textbooks and memoirs from this period. J. R Mott who joined the probation service in 1960 generally praised the police but noted (1992:113) that police and probation officers would not always agree because they 'deal with mutual clients in different ways'. Phyllida Parsloe (1967: 89-90) writing for social work students in the late 1960s advised:

The probation service has a special and important relationship with the police. Any officer will know how much the local police can either help or hinder his (sic) work. The relationship between these two services is never likely to be easy, for they represent distinct parts of society's mixed attitude to offenders, and different kinds of people will be attracted to each service.

Our more experienced interviewees, who joined probation in the 1960s and 1970s recalled working their 'patches' and having little interaction with the local police officers despite them covering similar areas on their beats. A significant feature of this period is that both services worked close to the same communities, though both were to retreat from them. First the police moved officers from foot patrols based around beats to motorised patrolling under the 'unit beat system' in the early 1970s (Weatheritt 1986). Subsequently this new system was held popularly responsible for damaging the traditional relationship between the beat officer and the public. From the late 1980s, the probation service were also to withdraw from being embedded in communities; the patch system gave way to office-based programme delivery and desk-bound risk management.

The patch system, which included undertaking regular home visits, enabled probation officers to build their field experience and to get to know families and individuals within relatively small geographical areas. Although the police were also working close to the community they were perceived as an oppositional force. One interviewee talked about working his patch on a council-owned housing estate in the mid-1970s: 
When I started, we let 'em out and the police locked 'em up, pretty much. And they hated us and we hated them [....] we were namby-pamby social workers and, you know, all that kind of thing, do-gooders; and the police were rough, tough, you know, keeping people safe and lock 'em up and throw away the key. And there was a complete culture divide between police and probation. (CO11)

Other interviewees confirmed that the relationship was not just one of indifference, but one of suspicion and hostility, often mutual (CO3; CO12; FPW2; CO16). This is captured by one interviewee who survived a formative experience by deflecting the hostility of police away from probation officers to social workers:

I was sent to do a talk to the police in about my second year of work...I got shoved in this room [with] about 30 kind of really old, experienced police sergeants, who just wanted to destroy the probation service... and the only way you survived was by mentioning social workers and then they all agreed that social workers were worse. (FPW6)

Suspicion existed at both individual and organisational levels. At management level this was evidenced by the absence of information sharing protocols between agencies. At the operational level of probation officers there was cultural and ideological opposition to providing information on clients to the police:

Police were very much kept at arm's length and you wouldn't share information with the police. I mean people would often tell you things but you would never have shared that. And there's probably an element of collusion with offenders, and obviously, that's something that changed. (PW16)

Thus far we have characterised the probation-police relationship in a way that suggests, at best, Davidson's first stage of inter-organisational relationships, namely 'communication'. However, although probation officers were wary of the police as an organisation, some were building informal mutually beneficial contacts with police officers that were to prove the groundwork for later enhanced relations. For example, several interviewees talked about mixing with police officers around the courts and talking cases through with them and, similarly, liaising with the police over child protection cases. This informal, possibly aberrant, behaviour was to be sanctioned formally, if not by the respective occupational cultures, with the passing of the Crime and Disorder Act in 1998 which coincided with other influential factors including a change in training regimes.

We now turn to more contemporary perceptions of these relationships.

\section{NOMS, the myth of 'prisobation' and the spectre of polibation}

The emergence of NOMS in 2004 can be characterised by the desire of the government to eradicate the concept of 'probation' from the national psyche and erode the professional identity of probation officers, while at the same time creating a narrative of 'joined up' ('seamless', 'end-to-end') penal thinking and cost-effective delivery of both public protection (through risk assessment) and services to offenders (through contestability) (Worrall 2008:120). What the Carter Report failed to appreciate, however, was the cultural shift that had already taken place within the probation service, away from closer working with prisons and towards a 'federal' relationship with the police. In our research we have been interested 
in identifying the impact of NOMS on probation officer cultures and, specifically, on relationships between probation and prison officers. We have found that the impact has been greatest at (a) senior management level and (b) at the level of probation officers and prison officers working together inside prison. The impact on probation officers working in the community has been either minimal (with experienced officers often refusing to use the term 'offender manager' in preference to 'probation officer'), taken-for-granted (among those staff who have been recruited and trained since 2004 - 'I'm a child of NOMS' (PW4)) or resistant:

[NOMS] was such a catastrophe....we're just poles apart...and all the fears are realised inasmuch as NOMS is run by prison staff, it's not run by probation staff...we've got people who know nothing about our job ...making huge decisions about us as a service. (PW19)

The comradeship and solidarity of prison officer culture, as described by Liebling et al. (2011) is still very recognisable, even if it is not always easy to explain:

The prison service are militaryfied and we're not - we're reflective thinkers...Just the way they carry themselves, the way they speak...like prison talk is very curt and quick, da, di, da, di, you know, want it done, this is what's gonna happen, you don't get into conversations and things. (PW23)

In this environment, probation officers feel vulnerable in their role. In the current financial climate, prison officers view them as being 'expensive and unnecessary' (PW8), and as 'middle class tossers, competing for their jobs' (PW17). Burnett and Stevens (2007) found that prison officers believed they would need to make very little adjustment to become offender supervisors and one of our respondents agreed that they regarded probation officers as redundant:

They basically hated us, like they didn't want us there, we were too expensive...I think they thought that the offender management model was, "this is it, we are probation officers now, you know, we don't need probation officers, we can do everything". (PW6)

Additionally, the rise and rise of prison psychologists (many of whom now run the accredited cognitive behavioural programmes) has further threatened the role of probation officers in prisons. One interviewee told us that she was shocked that the governor could simply decide that probation officers were no longer to run programmes (PW1). She complained that she was losing her skills and that she had been confined to chairing post-programme review meetings that were 'incredibly boring - it's like groundhog day' (PW1).

In some prisons at least, offender supervisors may be either prison officers or probation officers (suggesting the emergence of the 'prisobation' officer) but they don't necessarily do the job in the same way. Specifically, we were told that prison officers don't like, or don't have the skills, to write reports, so this task often falls to probation staff, who are also allocated higher risk offenders who are likely to be subject to higher level multi-agency supervision on release.

Other respondents were more optimistic and suggested that probation culture can mitigate the worst excesses of prison culture in ways that may not be immediately obvious. We were told that probation officers are often more challenging of prisoners than prison officers are. 
'There's a lot of appeasement here' (PW3) one senior probation officer told us. She argued that this was not in prisoners' interests and was the result of laziness and fear on the part of prison officers. Probation officers, she argued, put in more time and effort to help prisoners resolve their problems instead of taking the easy way out. She felt that prison staff who worked alongside probation staff were gaining these skills.

At senior management level, there was some criticism of the failure of probation's leaders to penetrate the top echelons of the NOMS hierarchy. The predominant view of NOMS was of a 'command and control' culture which no longer has any probation voice at the top:

The prison service is a service that is not institutionally and constitutionally capable of understanding that there's any other way of operating other than the way the prison service operates... and NOMS is the prison service, it's got no probation thinking in it...it's deeply frustrating. (CO2)

Probation is regarded as 'troublesome', we were told, because 'they don't do what they're told' (CO14). The implications of this are pervasive and reach beyond the scope of this article to the heart of the probation service's future. Arguably, relationships between the two services can no longer be accurately described as 'inter-agency' since they are now one and the same agency. On paper, they have reached Davidson's level 5 model, namely, that of merger but, while a 'turbulent' environment has been readily identified, our research suggests that obstacles to a genuine merger remain in the form of a threat to probation 'domain', a failure to resolve individual and group role conflicts and a perceived absence of probation leadership within the merged organisation.

In contrast, contemporary perceptions of relationships between probation and the police are generally more positive. Our research suggests that from the perspective of probation officers, relations with the police began to change from 1998. From this year the Crime and Disorder Act required local agencies, including probation and police, to work together and share information to identify and resolve crime issues. In practice this meant that police and probation employees would meet routinely and formally and would work together at strategic and operational levels. The closer cooperation was given further nudges towards coordination with the establishment of the MAPPA framework from 2000 and the widening of prolific offender projects from ad-hoc area-specific initiatives to a national scheme in 2002, which extended to a national PPO Strategy in 2004. Many of our interviewees in senior management roles referred to the changing relationship with the police as their most significant changed relationship. Some compared the mutually beneficial relationship with the police with the less coherent relationship with prisons:

I think relationships with the police are excellent. [...] . I mean when I was a new officer, you know, the police were the enemy, .... police officers didn't come into a probation office, [...] I think a huge change, you know, largely triggered by a whole MAPPA process. I mean not all of that is brilliant but ... and I think our natural allies actually are the police not the prison service. You know, I think the mistake was, if we had to go in with somebody, was to go in the prison service, not the police; I'd much rather be in with the police. (CO13)

At the same time that agencies were finding their way in formal partnership working, new training arrangements for probation officers were also set in place, from 1997, that separated probation and social work training, with the creation of Trainee Probation Officers (TPOs) and the Diploma in Probation Studies. Treadwell (2006) argues that although the intention of 
the new programme was not to create an unquestioning enforcement mentality in TPOs, it did have that consequence for some. In terms of working relations with the police, this raises the possibility that some probation officers who have qualified since 1997 are more likely to accept the police as co-workers than their colleagues are, who trained under previous regimes. And indeed we did find that interviewees tended to characterise themselves and their colleagues in terms of the qualification framework that they trained under.

For some of the older, more experienced, interviewees, the irony of the turnaround in organisational attitudes towards the police was not lost. One interviewee recalled an incident from the seventies when as a young probation officer she was chatting to police officers outside the police station behind the court:

I can remember my boss saying to me, if I catch you talking to a police officer again, you could get sacked, whereas now, if I don't talk to the police, I could get sacked. (PW24)

The turbulence of the environment had contributed, therefore, to creating the conditions after 1998 in which probation-police cooperation, coordination and even federation (in Davidson's sense of the terms) was deemed both appropriate and desirable. The Labour government funded the police to unprecedented levels and as probation retreated from the community due to resource constraints and the dominance of computer-based work, the police returned there through reassurance policing, neighbourhood policing teams and the introduction of Police Community Support Officers. Both probation and the police had different but converging motives for getting closer to each other and thereby to communities, united in the cause of public protection. In such conditions, the potential for mutual adjustment and respect for organisational domain is likely to be enhanced. There is evidence that probation-police partnership working can bring benefits for the effective management of offenders (see, for example, Mawby and Worrall 2004), especially when complementary skills are acknowledged. As one interviewee remarked:

We've transformed our relationships with the police now in ways that were unimaginable when I came into the job. [...] the reason why we work well with the police is because we're different to them, and from them. (CO2)

This point is reinforced by Nash $(2008: 303,307)$ who argues that multi-agency work should be about bringing different skills and knowledge bases together to add value when focusing on a problem or situation. Polibation, for him, raises the threat (and reality in public protection teams) of bringing together agency practitioners who become too similar and lose their distinct contributions and core cultural characteristics. The extent to which practitioners merge their practices or cross over to take on characteristics of their partners has been a recurring theme in both UK and US literature (Murphy and Lutze 2009; Nash and Walker 2009). Corbett (1998) coined the term 'mission distortion' to describe practitioners drifting towards their partner's way of seeing things. Our research provided examples of practitioners moving in the direction of their partner agencies. Interviewees recounted examples of police officers who had become focussed on rehabilitation which when combined with their own 'can do' approach sometimes had unfortunate consequences:

[Of PPO officers] What always makes me laugh is, I became the bad cop and they became the good cop...because the police are very much "there's a problem, let's sort it" ...but I had the licence, I was the one with the power...certainly in the offenders' eyes, I seemed to be the baddie. (PW6) 
[Of PPO colleague] He's a smashing guy but he's a bobby, you know, and he comes across as, you know [laugh]. He's.... he's a people person in a non-people person way. He's.... err police are quite black and white, you know, just in the way that they approach stuff. You know, there's a problem, we can solve it. Yes. .... a very pragmatic approach to it, you know; tell me your problem, I'll give you a solution or a way you can do it, and then go and do it, yeah. Without the subtleties of human interaction, you know. I think that's the thing about it [laugh]. (PW17)

By the same measure, interviewees provided examples of probation colleagues moving in the opposite direction:

The TPOs, no disrespect to the TPOs, they work completely differently .... they're into "get 'em". You hear them so often "I've got 'em". I've heard it so often. I'll say you've got who, you know, and they say well, I can breach him now, .... I say is that what your job's about you know, grabbing hold of him, breaching him? Isn't it about like going out and negotiating and pulling 'em in a little bit? And they don't see that, a lot of them. (PW23)

The structural transformations that enabled closer working relationships may have fed into the cultural transformations that we have described but this is not the complete picture and we would argue that Davidson's model is thus over-simplified. Just as in the pre-1998 period we found pockets of co-operation amid the general mutual stand-off, in the post-1998 era there exists within the general spirit of openness and co-operation cultural continuities in both agencies that emphasise that these are two different agencies with separate missions that at times coincide and coalesce but at other times reinforce traditional suspicions. For example, the excesses of police culture are still evident and were put forward by one interviewee as her reason for leaving the police and training as a probation officer:

[I] was only in the police for about 18 months, realised that it wasn't for me. And then applied for the probation training and got accepted. [...] I knew that culturally, being a police officer wasn't for me. The culture of the police, it didn't fit with my view of criminal justice, I guess. And I.... I just didn't feel comfortable. [...] .... some of the negativity about me being a graduate; negativity about me being female. Um and I just realised quite quickly that I didn't wanna just lock people up and move onto the next prisoner (PW19)

Equally, while interviewees working at an operational level provided examples of strong working relations with some police officers, there was an equivalent number of comments that referred to the tensions that remain, arising from, inter alia, police propensity to try and take over offender management 'because they're always much bigger and stronger' (CO14) and their perceived lack of empathy and understanding:

They just don't get the whole softly-softly, catchy monkey approach. It's very much let's get in there and crack some skulls. So obviously, sometimes they can be a bit frustrated with our way of working in terms of the slower way, [...] I think some of them probably just don't see our work as any value . [...] I mean they're not really interested in people, are they, post-sentence, coppers? They don't really care. (PW15)

\section{Conclusion}

In this article, we have demonstrated that the political, economic and social landscape of the past five decades, but particularly since the late 1980s, has created a 'turbulent field' which no single criminal justice agency can navigate alone. The old regime of minimal communication between police and probation proved wholly inadequate for the demands of 
community safety, public protection and risk management. We argue here (see Table 1) that probation-police relations moved dramatically through Davidson's levels in the late 1990s to a relationship of 'federation' where formal joint structures exist for at least some objectives and tasks within the two organisations. The relationship between probation and prison is more complex, having been one of uneasy co-operation from the 1960s to the 1980s, followed by a gradual move to 'federation' and a forced move to 'merger' by 2004.

\begin{tabular}{|l|l|l|l|}
\hline \multicolumn{1}{|c|}{$\begin{array}{c}\text { Probation } \\
\text { relationships }\end{array}$} & \multicolumn{1}{|c|}{ Pre-1998 } & \multicolumn{1}{c|}{ P998 } & \multicolumn{1}{c|}{ Post-1998 } \\
\hline With Prisons & $\begin{array}{l}\text { Co-operation (The } \\
\text { Welfare) moving to } \\
\text { Co-ordination (Shared } \\
\text { Working) }\end{array}$ & $\begin{array}{l}\text { Joining Forces to } \\
\text { Protect the Public }\end{array}$ & $\begin{array}{l}\text { Federation (e.g. } \\
\text { accredited programmes, } \\
\text { resettlement) } \\
\text { accelerating to Merger } \\
\text { (Carter Report and } \\
\text { NOMS) }\end{array}$ \\
\hline With Police & $\begin{array}{l}\text { Communication (mutual } \\
\text { suspicion) with pockets } \\
\text { of Co-operation }\end{array}$ & $\begin{array}{l}\text { Crime and } \\
\text { Disorder Act }\end{array}$ & $\begin{array}{l}\text { Federation (Public } \\
\text { protection partnerships } \\
\text { e.g. PPO, MAPPA) }\end{array}$ \\
\hline
\end{tabular}

Table 1. Adapting Davidson's model to probation-prisons-police relationships

There was a potential 'tipping point' in the late 1990s when it seemed possible that all three organisations might 'federate' but the turbulent environment swept probation (reluctantly) and prisons in another direction. Our research indicates that probation perceives itself to have suffered as a result, not least because its domain has been threatened by the merger, role conflicts remain unresolved and there is a perceived absence of probation leadership at the top of the new organisation. However rational the merger may have seemed to Carter and to policy-makers, there are limits to rationality that were not taken into account. Despite the deeply embedded historical animosity between probation officers and the police, the former now 'fantasise' about what might have been, had they merged with the police.

Yet, as we have shown, there remain strong perceived cultural continuities in all three organisations that create tensions which might be regarded as being healthy in co-operative or federated organisations but as being toxic in merged organisations. If our analysis has any validity then healthy relationships between probation, police and prisons require a realignment that ensures respect for the domain of each in the interests of the wider community.

\section{Notes}

1. We gratefully acknowledge the funding provided by the ESRC (grant reference RES000-22-3979: Probation officers, their occupational cultures and offender management). Full report available from the authors after the completion of the project in November 2011.

2. In presenting data from the interviews, we have categorised the participants as follows: (1) ' $\boldsymbol{P W}$ ' are current probation workers and comprise: probation service officers, trainee probation officers, probation officers and senior probation officers; (2) ' $\boldsymbol{C O} \boldsymbol{s}$ ' are chief officer grades, namely assistant chief officers and chief executive officers; and (3) ' $\boldsymbol{F P W s}$ ' are former and retired probation workers. 


\section{References}

Audit Commission (1998) A fruitful partnership - effective partnership working. London: Home Office.

Ashforth, B.E. et al. (2007) 'Normalizing dirty work: managerial tactics for countering occupational taint', Academy of Management Journal 50(1): 149-174.

Berry, G., Briggs P., Erol, R., and van Staden, L. (2011) The effectiveness of partnership working in a crime and disorder context: A rapid evidence assessment. Home Office Research Report 52.

Burnett, R. and Stevens, A. (2007) 'Not of much significance (yet): NOMS from the perspective of prison staff’, Prison Service Journal 172: 3-11.

Carter, P. (2003) Managing Offenders, Reducing Crime: A New Approach. London: Home Office.

Corbett, R. (1998) 'Probation blue: The promise (and perils) of probation-police partnerships', Correctional Management Quarterly 2,31-39.

Crawford, A. (1998). 'Community safety and the quest for security: holding back the dynamics of social exclusion', Policy Studies 19, 237-253.

Davidson, S. (1976) 'Planning and coordination of social services in multi-organisational contexts', Social Services Review 50, 117-37.

Emery, F.E. and Trist, E.L. (1965) 'The causal texture of organizational environments', Human Relations 18: 21-32.

Fieldhouse, P. and Williams, T. (1986) 'Shared working in prison', Probation Journal 33( 4): 143-147.

Glanfield, P. (1985) ‘Withdrawal from prisons policy’, Probation Journal 32(2): 66.

Glasby, J. and Littlechild, R. (2004) The health and social care divide: the experiences of older people, $2^{\text {nd }}$ edition. Bristol: Policy Press.

Home Office (1998) Joining Forces to Protect the Public. London: Home Office.

Jepson, N. and Elliott, K. (1985) Shared working between prison and probation officers. London: Home Office.

Kemshall, H. and Maguire, M. (2001) 'Public protection, partnership and risk penality: the multi-agency risk management of sexual and violent offenders', Punishment and Society 3(2): 237-64. 
Kreiner, G. E. et al.(2006) 'Identity dynamics in occupational dirty work: integrating social identity and system justification perspectives', Organization Science 17(5): 619-636.

Lacey, M. and Read, G. (1985) 'Probation working in prison', Probation Journal 32(2): 6165.

Leech, M. (1991) 'Recommended for release', Probation Journal 38(1): 10-14.

Liebling, A., Price, D. and Shefer, G. (2011) The Prison Officer, $2^{\text {nd }}$ Edition. Cullompton: Willan Publishing.

Lindblom, C.E. and E.J. Woodhouse (1993) The Policy Making Process, $3^{\text {rd }}$ edition. New Jersey: Prentice Hall.

Maguire, M. (2007) 'The resettlement of ex-prisoners' in L. Gelsthorpe and R. Morgan (Eds) Handbook of Probation. Cullompton: Willan Publishing, 398-424.

Mawby, R.C. and Worrall, A. (2004) 'Polibation revisited: policing, probation and prolific offender projects', International Journal of Police Science and Management 6(2): 63-73.

Mawby, R.C., Crawley, P. and Wright, A. (2005) 'Beyond polibation and towards prisipolibation? Joint agency offender management in the context of the Street Crime Initiative', International Journal of Police Science and Management 9(2): 122-34.

Morgan, J (1991) Safer Communities: the local delivery of crime prevention through the partnership approach. Report of the Home Office Standing Conference on Crime Prevention. London: Home Office.

Mott, J.R. (1992) Probation, prison and parole: A true story of the work of a probation officer. Lewes: Temple House Books.

Murphy, D. and Lutze, F. (2009) 'Police-Probation partnerships: Professional identity and the sharing of coercive power', Journal of Criminal Justice 37,65-76.

Nash, M. (1999) 'Enter the 'polibation officer', International Journal of Police Science and Management 1(4): 360-368.

Nash, M. (2004) 'A reply to Mawby and Worrall', International Journal of Police Science and Management 6(2): 74-76.

Nash, M. (2008) 'Exit the polibation officer? Decoupling police and probation', International Journal of the Sociology of Law 10(3): 302-312.

Nash, M. and Walker, L. (2009) 'Mappa - is closer collaboration really the key to effectiveness?' Policing 3(2): 172-180.

National Audit Office (2001) Joining up to improve public services. London: HMSO. 
Nellis, M. (2007) 'Humanising justice: the English Probation Service up to 1972' in L. Gelsthorpe and R. Morgan (Eds) Handbook of Probation. Cullompton: Willan Publishing, 25-58.

Othen, M.J. (1975) 'Prison welfare - time to think again?' Probation Journal 22(4): 98-103.

Parsloe, P. (1967) The work of the Probation and After-Care Officer. London: Routledge and Kegan Paul.

Pratt, M. (1975)' Stress and opportunity in the role of the Prison Welfare Officer', British Journal of Social Work 5(4): 379-396.

Priestley, P. (1972)' The Prison Welfare Officer: a case of role strain', British Journal of Sociology 23(2):221-235.

Rumgay, J. (2003) 'Partnerships in the probation service' in W.H.Chui and M. Nellis (Eds) Moving Probation Forward. Harlow: Pearson Education, 195-213.

Stanton, A. (1985) 'Why Probation isn't working in prison', Probation Journal 32(3): 107108.

Stone, N. (1986) 'In discussion with the POA' Probation Journal 33(3): 81-86.

Thomas, T. (1994) The police and social workers, $2^{\text {nd }}$ edition. Aldershot: Ashgate.

Treadwell, J. (2006) 'Some personal reflections on probation training', The Howard Journal 45(1): 1-13.

Weatheritt, M. (1986) Innovations in Policing. London: Croom Helm.

Williams, B. (1991) 'Probation contact with long term prisoners', Probation Journal 38(1): 4-9.

Worrall, A. (2008) 'The "seemingness" of the "seamless management" of offenders' in P. Carlen (Ed) Imaginary Penalities. Cullompton: Willan Publishing, 113-134.

Worrall, A. and Hoy, C. (2005) Punishment in the Community: Managing offenders, making choices. Cullompton: Willan Publishing. 